\title{
Surgical site infections following spine surgery: eliminating the controversies in the diagnosis
}

\author{
Jad Chahoud ${ }^{\dagger}$, Zeina Kanafani ${ }^{\dagger}$ and Souha S. Kanj* \\ Division of Infectious Diseases, Department of Internal Medicine, American University of Beirut Medical Center, Beirut, Lebanon
}

\section{Edited by:}

Christina Maria Joseph Elisabeth

Vandenbroucke-Grauls, VU University

Medical Center, Netherlands

\section{Reviewed by:}

Saara Vainio, VU University Medical Center, Netherlands

Andread Voss, Canisius-Wilhelmina

Ziekenhuis and Radboud University

Nijmegen Medical Centre,

Netherlands

\section{${ }^{*}$ Correspondence:}

Souha S. Kanj, Infection Control and Prevention Program, Division of Infectious Diseases, Department of Internal Medicine, American

University of Beirut Medical Center, PO Box 11-0236, Riad El Solh, Beirut 1107 2020, Lebanon

e-mail: sk11@aub.edu.lb

${ }^{\dagger} J a d$ Chahoud and Zeina Kanafani have contributed equally to this work
Surgical site infection (SSI) following spine surgery is a dreaded complication with significant morbidity and economic burden. SSIs following spine surgery can be superficial, characterized by obvious wound drainage or deep-seated with a healed wound. Staphylococcus aureus remains the principal causal agent. There are certain pre-operative risk factors that increase the risk of SSI, mainly diabetes, smoking, steroids, and peri-operative transfusions. Additionally, intra-operative risk factors include surgical invasiveness, type of fusion, implant use, and traditional instead of minimally invasive approach. A high level of suspicion is crucial to attaining an early definitive diagnosis and initiating appropriate management. The most common presenting symptom is back pain, usually manifesting 2 4 weeks and up to 3 months after a spinal procedure. Scheduling a follow-up visit between weeks 2 and 4 after surgery is therefore necessary for early detection. Inflammatory markers are important diagnostic tools, and comparing pre-operative with post-operative levels should be done when suspecting SSIs following spine surgery. Particularly, serum amyloid $A$ is a novel inflammatory marker that can expedite the diagnosis of SSIs. Magnetic resonance imaging remains the diagnostic modality of choice when suspecting a SSI following spine surgery. While 18F-fluorodeoxyglucose-positron emission tomography is not widely used, it may be useful in challenging cases. Despite their low yield, blood cultures should be collected before initiating antibiotic therapy. Samples from wound drainage should be sent for Gram stain and cultures. When there is a high clinical suspicion of SSI and in the absence of superficial wound drainage, computed tomography-guided aspiration of paraspinal collections is warranted. Unless the patient is hemodynamically compromised, antibiotics should be deferred until proper specimens for culture are secured.

\section{Keywords: post-surgical spine infection, post-procedural discitis, imaging, risk factors, Staphylococcus aureus,} inflammatory markers

\section{INTRODUCTION}

Surgical site infections (SSIs) following spine surgery comprise superficial and deep infections and were first described as a clinical entity by Turnbull in 1953 (1). Superficial spine infections are localized to the skin and subcutaneous tissue. On the other hand, deep infections disseminate under the fascia and encompass discitis, epidural abscess, and spondylitis; this type of infections is characterized by inflammation of the intervertebral disks and associated soft and articular tissues (2).

Although SSIs following spine surgery can be prevented to a great extent using general measures intended to avert all potential SSIs, they remain a dreaded complication. Some of these general preventive approaches include adoption of aseptic techniques, optimization of patient status pre-operatively as well as intra-operatively, appropriate use of pre-operative antibiotics, and good post-operative follow-up (3-6). SSIs result in significant increase in morbidity and incur a substantial cost to the health care system (7). In one study, each episode of wound infection following spine procedure contributed to a mean increase in the cost of care by $\$ 4,067(\mathrm{CI}, \$ 1,682.79-6,872.39)$; $(P=0.0004)$ compared to a non-complicated case (8). A high index of suspicion is compulsory in every patient presenting with back pain after any invasive diagnostic or therapeutic spinal procedure (9). Physicians may sometimes struggle with diagnosing SSI due to a number of difficulties, including the paucity of physical examination findings, mimicry of non-infective conditions, presence of minor symptoms leading to patients not seeking medical attention, inadequate follow-up strategies in some institutions, and the previous dependence on plain X-rays that lack sensitivity for diagnosing SSI (10).

However, the use of a well-defined systematic approach would help in establishing a definitive diagnosis in a timely manner. This would be based on a comprehensive history, thorough physical examination, detailed laboratory studies, blood cultures, and cultures of wound or computed tomography (CT)-guided aspirate material, and imaging studies.

In this paper, we attempt to provide a comprehensive review on the diagnostic approach to SSIs following spine surgery. We discuss the incidence of SSIs based on type of procedure, detailing the factors that place patients at increased risk for infection and highlighting the spectrum of involved pathogens. We also review clinical, laboratory, and imaging techniques in the diagnosis of SSI, 
addressing some of the controversies. Treatment of SSIs is beyond the scope of this article and will not be reviewed here.

\section{EPIDEMIOLOGY}

The reported incidence of SSIs following spine surgery ranges from 0.5 to $18.8 \%$ (11-19). Such wide-ranging results from different reports are most probably due to significant variations in operative factors such as the use of implants, case complexity, and the surgical approach itself. Additionally, in some cases, the discitis may be self-limited and may not be reported to the surgeon, whereas in other cases, patients may suffer from fulminant sepsis with abscess development.

A crucial need exists for documentation of an exact incidence of SSIs at every center depending on the surgical procedure. This will direct pre-operative patient counseling, improve quality of care, enhance the effectiveness of infection control measures, and potentially alleviate medico-legal concerns.
Table 1 summarizes studies that have looked at the incidence of SSI following spine surgery and that provided data on type of surgery and type of infection. The largest study by Smith et al. included a total of 108,419 patients from 2004 to 2007. The primary endpoint of the study was to estimate the incidence of SSIs and the secondary endpoint was to assess risk factors for infection (20). Infections were deemed to be superficial in $0.8 \%$ and deep in $1.3 \%$ of cases. Other studies in heterogeneous surgical conditions between 2001 and 2012 (Table 1) reported infection rates from 0.15 to $7.2 \%(20-33)$.

Infection rates vary greatly according to type of initial surgical intervention (Table 2) $(16,20,34)$. Notably, surgeries for spinal trauma are associated with the highest SSI rates, reported to be $9.4 \%$ in one study (20). Patients undergoing spine surgeries for metastatic tumor and acute osteodiscitis constitute two other subgroups with high infection rates of around $5 \%$. On the other hand, surgeries for degenerative disease have the lowest reported

Table 1 | Prospective and retrospective clinical studies on incidence of SSI incidence following spine surgery (20-33).

\begin{tabular}{|c|c|c|c|c|c|}
\hline Reference & Study design & $\begin{array}{l}\text { Type of interventional } \\
\text { procedures }(\%)\end{array}$ & $\begin{array}{l}\text { Type of SSI considered } \\
\text { in the study }\end{array}$ & $\begin{array}{l}\text { Number of total } \\
\text { study patients }\end{array}$ & SSI rate $(\%)$ \\
\hline (20) & $\begin{array}{l}\text { Retrospective review of } \\
\text { prospectively collected data }\end{array}$ & $\begin{array}{l}\text { Invasive (87); minimally } \\
\text { invasive (13) }\end{array}$ & Superficial or deep & 108,419 & 6.7 \\
\hline$(21)$ & $\begin{array}{l}\text { Retrospective review of } \\
\text { prospectively collected data }\end{array}$ & $\begin{array}{l}\text { Decompressive (78); } \\
\text { instrumented (20); } \\
\text { intra-dural (2) }\end{array}$ & Superficial or deep & 1,274 & 0.22 \\
\hline$(22)$ & Retrospective data review & $\begin{array}{l}\text { Decompressive (89); } \\
\text { instrumented (1.4) }\end{array}$ & Superficial or deep & 663 & 0.15 \\
\hline (23) & Retrospective case-control study & $\begin{array}{l}\text { Decompressive (27.4); } \\
\text { instrumented (72.5) }\end{array}$ & Superficial or deep & 2,316 & 2.0 \\
\hline (25) & Retrospective data review & Instrumented fusions (100) & Deep only & 1,980 & 3.7 \\
\hline (24) & Case-control study & Laminectomy (100) & Superficial or deep & 6,365 & 1.0 \\
\hline (28) & Retrospective data review & $\begin{array}{l}\text { Instrumented posterior (82); } \\
\text { anterior (18) }\end{array}$ & Deep only & 326 & 4.3 \\
\hline (26) & Retrospective data review & $\begin{array}{l}\text { Decompressive (60); } \\
\text { instrumented (40) }\end{array}$ & Deep only & 1,133 & 0.7 \\
\hline (27) & Retrospective data review & $\begin{array}{l}\text { Instrumented posterior } \\
\text { interbody fusion (100) }\end{array}$ & Deep only & 111 & 7.2 \\
\hline (33) & Prospective case-control study & $\begin{array}{l}\text { Mixed decompressive and } \\
\text { instrumented }\end{array}$ & Superficial or deep & 997 & 2.7 \\
\hline (29) & Retrospective case-control & $\begin{array}{l}\text { Mixed decompressive and } \\
\text { instrumented }\end{array}$ & Deep only & 1,095 & 4.4 \\
\hline (30) & Retrospective case-control study & $\begin{array}{l}\text { Mixed decompressive and } \\
\text { instrumented }\end{array}$ & Superficial or deep & 1,918 & 2.8 \\
\hline (31) & Prospective surveillance study & Laminectomy & Nosocomial infection & 37,137 & $0.9-2.6$ \\
\hline (31) & Prospective surveillance study & Spinal fusion & Nosocomial infection & 21,491 & $1.2-7.2$ \\
\hline$(32)$ & Retrospective data review & $\begin{array}{l}\text { Instrumental lumbar } \\
\text { fusion (100) }\end{array}$ & Deep only & 817 & 3.2 \\
\hline (34) & Retrospective data review & $\begin{array}{l}\text { Mixed decompressive } \\
\text { and instrumented }\end{array}$ & Deep only & 2,391 & 1.9 \\
\hline
\end{tabular}


Table 2 | Rate of SSI following spine surgery by type of surgery

\begin{tabular}{lc}
\hline Type of surgery (reference number) & Rate of SSI (\%) \\
\hline Trauma (20) & 9.4 \\
Acute discitis (20) & 5.1 \\
Metastatic tumor (20, 34) & 5.1 \\
Kyphosis (20) & 4.2 \\
Scoliosis (20) & 3.7 \\
Elective spinal surgery (20) & 3.7 \\
Implant revision (20) & 3.2 \\
Non-minimally invasive (20) & 2.4 \\
Degenerative disease (20) & 1.4 \\
Minimally invasive approach (16, 20) & 0.5 \\
\hline
\end{tabular}

infection rate of $1.4 \%$. Moreover, minimally invasive spinal procedures seem to be associated with a much lower infection rate than open procedures ( 0.5 vs. $2.4 \%, P=0.001)(20)$. In the study by Smith et al., the overall rate of infection among adults varied depending on the location of spine surgery. The highest rates were for thoracic procedures $(2.1 \%)$, followed by lumbar $(1.6 \%)$ and cervical procedures $(0.8 \%)(20)$. Other factors that affect infection rates include the nature of the surgical procedures. Spinal fusion had a 33\% higher risk of infection than procedures without fusion (20). In addition, infections rates vary depending on the approach to spinal fusion. For instance, cases with anterior fusion only showed significantly lower infection rates $(0.6 \%)$ compared to the overall rate of infection associated with fusion cases. This lower infection rate with the anterior approach may be explained by less extensive muscle dissection for bone exposure and the better vascularity of the anterior spine. For the other types of fusion, significantly higher infection rates were reported. These included combined anterior-posterior fusions (3.2\%), posterolateral-only fusions (3.0\%), and interlaminar facet-only fusions (2.8\%) (20).

The presence of implants is another factor that significantly increases SSI risk. Cases with instrumentation have resulted in a $28 \%$ higher infection rates than cases without implants (20). Implants provide an avascular surface for the bacteria to form a biofilm and constitute a nidus for microbial growth, hence escaping antibiotic activity and the host immune system.

In addition, revision cases are associated with a $65 \%$ higher rate of infection compared with primary cases. This significant increase in infection rates was even more evident for deep wound (2.2 vs. $1.2 \%$ ) compared with superficial wound infections (1.1 vs. $0.8 \%)(20)$.

\section{SPECIFIC RISK FACTORS FOR SSI DEVELOPMENT}

The incidence of SSIs is determined by both pre-operative and intra-operative risk factors. Several pre-operative patient factors (Table 3) have been incriminated in significantly increasing SSI risk. Diabetes (35) and cigarette smoking (28) for instance, are both associated with tissue ischemia and small vessel damage, predisposing to increased risk of infection. In addition, obesity constitutes a risk factor for SSI due to the thick layer of adipose tissue in obese patients, characterized by poor perfusion and presenting a large space for potential infective processes (28). Other identified peri-operative risk factors for SSI include steroid use
Table 3 | Surgical site infection pre-operative risk factors $(28,34-38)$.

Diabetes

Cigarette smoking

Obesity

Steroid use

Alcohol abuse

Extremes of ages

Peri-operative transfusion of blood products

Table 4 | Intra-operative factors associated with high risk for SSI $(20,28,36,39-44)$.

Surgical invasiveness index

Type of fusion performed

Implants use

Revision intervention (compared to primary intervention)

Traditional open approach (compared to minimally invasive approach)

Site of surgery (dorsal surgeries with highest infective risk compared to cervical and lumbar locations)

Omission of drain usage post spine surgery

Administered fraction of inspired oxygen less than $50 \%$

Operative duration above $3 \mathrm{~h}$

Instrumentation alloy from stainless steel (compared to titanium use)

$(23,36)$, alcohol abuse $(28,37)$, extremes of ages $(28,36,37)$, and transfusion of blood products (38).

In addition to pre-operative risk factors, multiple surgical factors have been assessed for their association with the occurrence of spinal infections (Table 4) (20, 28, 34-44).

The assessment of both pre-operative and intra-operative risk factors is mandatory according to best clinical practice. This would aid physicians in their operative approach choices and would allow closer follow-up for high-risk patients. We suggest the prospective development of an SSI risk score that would be inclusive of the relevant risk factors (Tables 3 and $\mathbf{4}$ ). There is a need to conduct studies aiming at generating this risk score based on reliable evidence. This score would be used as a tool to limit the ambiguity in the management and follow-up of patients undergoing spine surgery. The NHSN SSI standardized infection ratio (SIR) risk adjustment model can serve as a guide for the development of a specific one for spine surgeries (45).

\section{MICROBIAL ETIOLOGY}

Confirming the microbial etiology of SSI following spine surgery is of paramount importance to appropriately guide antimicrobial therapy. This is specifically important in the era of increasing antimicrobial resistance. Empirical antibiotic therapy is highly discouraged before obtaining the proper specimens for cultures (46, 47 ). Blood and wound cultures are recommended in patients presenting with suspected SSIs. When a deep collection is localized, obtaining a CT-guided specimen for Gram stain and culture is highly recommended. When surgical intervention is indicated and 
removal of implants is done for curative treatment, vortexing and sonication of the extracted implants to release biofilm-embedded organisms have shown an improvement in the diagnostic yield. Cultures from sonicated spinal implants have reported sensitivity and specificity rates of 93 and 97\%, respectively, for confirming the causative pathogen (48).

Surgical site infection following spine surgery usually occurs through direct inoculation during the surgical procedure. The other two possible routes of infection are hematogenous spread and early post-operative contamination. Staphylococcus aureus remains the leading agent of SSI responsible for around 50\% of cases, although estimates in various studies range from as low as $12-65 \%(12,28,48-50)$. Additional common causes of SSI include coagulase-negative staphylococci, mainly Staphylococcus epidermidis, mostly associated with implanted spinal prosthesis. In addition, Gram-negative organisms can be encountered, including Pseudomonas aeruginosa, Escherichia coli, and Proteus species (9). Gram-negative organisms are more likely to occur in cases of hematogenous seeding, and in lower lumbar surgical interventions due to proximity to the perianal area. Additional risk factors for SSI with Gram-negative bacteria include bladder or fecal incontinence, a previous history of long hospital admission and a posterior lumbosacral surgical approach (51). A history of intravenous drug use has also been associated with an increased risk of Gram-negative pathogens $(9,52)$. Recognizing all these risk factors would help in guiding empirical antimicrobial therapy pending culture results.

More recently anaerobic microorganisms such as Propionibacterium acnes, part of the normal skin flora, have been increasingly reported to cause various orthopedic-related SSIs including spine surgeries (53-55). P. acnes is difficult to detect in patients undergoing spinal surgery with instrumentation (56). Patients with $P$. acnes infection have a typical clinical presentation. They are usually in the fifth or sixth decade of life. They present with low-grade or no fever following a posterior spinal fusion and instrumentation and often present with a late (more than 30 days) post-surgical back pain as a sole complaint (55). Other than its usual indolent and delayed post-procedural clinical presentation, two additional reasons may explain the under-diagnosis of $P$. acnes SSI. First, this organism is considered as a low virulence skin organism, and thus is ignored in some cases to be the causative agent in SSI. Second, $P$. acnes is a slow growing microorganism that requires extended incubation time for growth (52). Thus, when this organism is suspected, several deep tissue specimens should be obtained and cultured for extended periods.

\section{DIAGNOSIS}

Establishing the diagnosis of SSI can be very challenging, and a high index of suspicion should always be maintained for any patient presenting with back pain within a window period of 3 months after the procedure. Figure 1 represents an algorithm for a diagnostic approach to suspected surgical spine infections and is detailed in the following sections. A number of difficulties may delay the confirmation of SSI. Although the usual duration between the invasive procedure and the occurrence of the infection ranges from 2 to 30 days (57), many indolent organisms like P. acnes, Serratia marcescens, diphtheroids, and coagulase-negative staphylococci classically present after 30 days (34). In addition, patients may not seek early medical attention since infection may present initially with minimal back pain as the only clinical finding and the lack of prompt medical follow-up after the procedure may therefore aggravate the problem $(28,52)$.

There remains a need for large multi-center clinical studies to address the optimal diagnostic approach for SSI. In this section, we will analyze currently available diagnostic modalities and the controversies that surround them.

\section{CLINICAL PRESENTATION}

The most common presenting symptom for SSI following spine surgery is back pain, usually 1 month after the procedure with a range of 2 days to over 3 months post-intervention (57). Studies focusing on spinal procedures with instrumentation showed that the onset of SSI is more delayed in this category of patients, with a mean time to SSI diagnosis of 14 months, thus underlying the need for long-term follow-up subsequent to instrumented spinal procedures (25). The pain is characteristically localized, continuous, and not relieved by pain medications. It can radiate to the hip, leg, scrotum, groin, abdomen, or perineum. It has a slow, insidious onset, which can cause diagnosis to be delayed. It could appear after a pain-free interval for as long as 3 months (29). Other characteristic clinical features are wound drainage and constitutional symptoms such as fever, present in $40 \%$ of the cases, fatigue, and weight loss $(28,57)$.

Additionally, physical examination may reveal localized tenderness, warmth, erythema, and edema at the site of surgery with or without purulent wound drainage (9). Purulent wound drainage occurs in around two-third of SSIs with instrumentation and is the most frequent indicative sign of instrumented spine surgery infections (48).

Deep infections present more commonly with constitutional symptoms, and in rare cases, patients might suffer from severe sepsis and end organ failure. Deep infections often lack impressive superficial features making their diagnosis solely presumptive.

\section{INFLAMMATORY MARKERS}

The most frequently used laboratory tests for both the diagnosis and follow-up of patients suspected to have SSI following spine surgery are: white blood cell count (WBC), differential erythrocyte sedimentation rate (ESR), and C-reactive protein (CRP). The WBC is elevated in less than $50 \%$ of SSI cases, thus making it an unreliable diagnostic marker (58). Although CRP and ESR are highly sensitive in the detection of any SSI, many barriers face their use in daily practice. ESR and CRP levels increase post-operatively rendering the differentiation between infected and non-infected patients problematic in the early post-operative window period. In fact, CRP levels possess low positive predictive values (31\%) in the diagnosis of SSI (59). For instance, CRP levels peak on day 3 and decrease to normal baseline between days 10 and 14 post-operatively (60). On the other hand, ESR levels are highest at around 14 days and do not normalize until approximately 6 weeks after surgery. The earlier normalization of CRP and its higher sensitivity in diagnosing SSI compared to ESR (95 vs. $80 \%$ ) make it a more useful tool (60-64). In cases of suspected SSI, it would be very useful to compare CRP levels at day 7 to those on day 


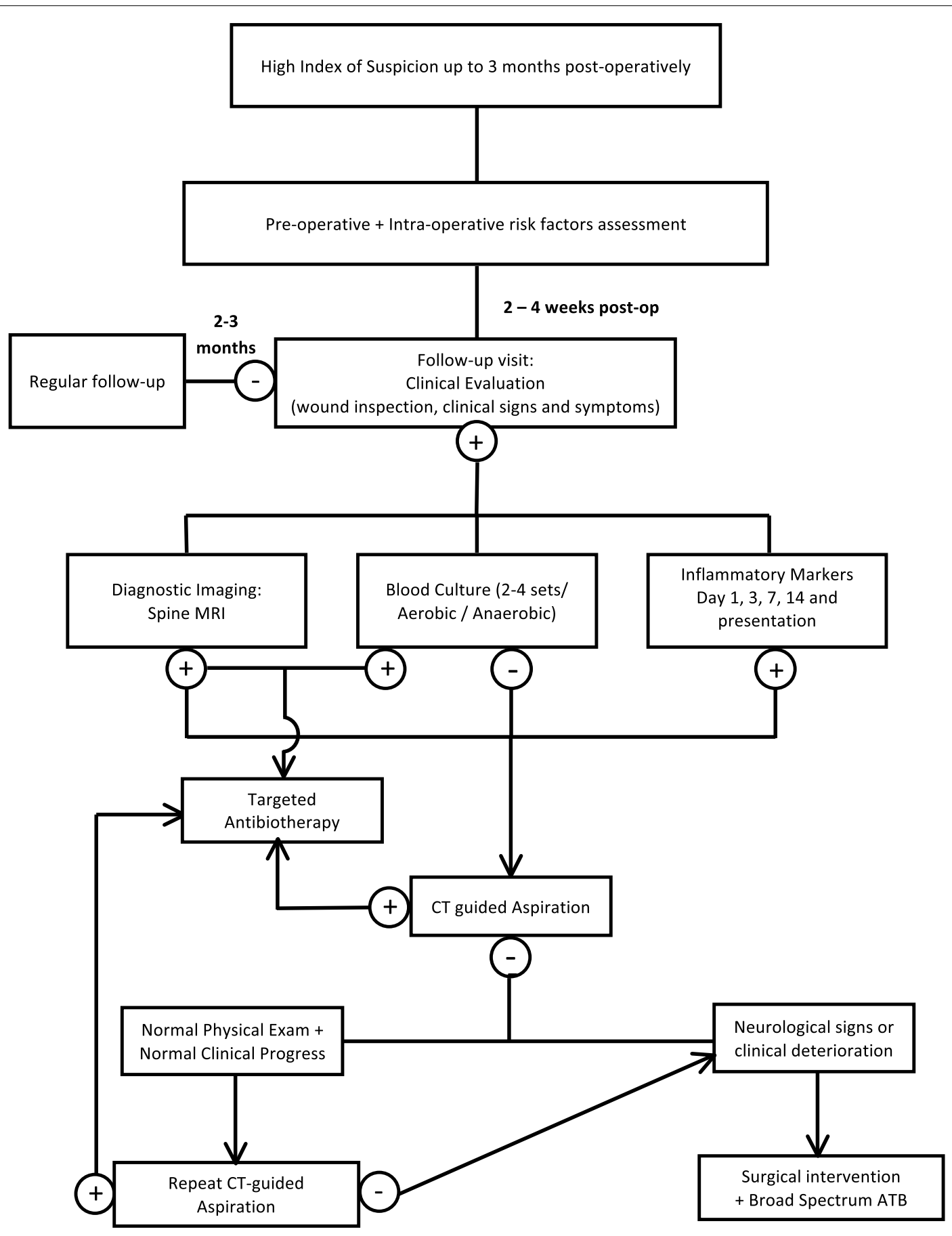

FIGURE 1 |Algorithm for rapid diagnosis and management of post-surgical spine infections

3; a detected elevation on day 7 would raise the suspicion for an infective process.

Some factors have been reported to influence CRP level. These include the amount of blood loss, the pre-operative CRP level, and the location of spinal intervention. For example, surgeries on the lumbar region were found to be associated with higher post-surgical levels of CRP compared to procedures involving other regions (62).

In view of these uncertainties surrounding the use of inflammatory markers as diagnostic tools for SSI, additional tools are desirable to distinguish between infected and non-infected patients in the post-operative period. 
Serum amyloid A (SAA), conventionally considered for its role in the pathogenesis of amyloid A-type amyloidosis, has been recently studied for its immunological activities, specifically its function in activating Toll-like receptor (TLR) 2 and TLR4, class B scavenger receptor CD36. A study by Deguchi et al. compared the serum levels of CRP and SAA after posterior approach spine surgery. The authors found that both markers achieved their highest levels on day 3. Although the levels later decreased, the rate of normalization of SAA was faster compared to CRP. SAA has a short half-life of $50 \mathrm{~min}$ compared to 5-7 h for CRP. This distinctive rapid decrease in SAA in noninfected cases is very helpful in eliminating one of the controversies surrounding the diagnosis of early SSI (65). Another remarkable finding in this study was that with the administration of corticosteroids, while the serum level of CRP decreases or even normalizes, that of SAA is not altered. Additionally, SAA levels did not vary with gender or age, and the marker preserved reactivity in patients with rheumatoid arthritis receiving corticosteroid therapy. Therefore, SAA can be considered a better inflammatory marker in the assessment of SSI following spine surgery (65).

Other inflammatory markers such as procalcitonin have been less promising in the diagnosis of SSI (66). One study compared the level of procalcitonin in 17 patients with spondylodiscitis and 18 patients with herniated disks and found no elevation in either group.

Our recommended approach for a comprehensive follow-up of patients undergoing invasive spinal procedures is using inflammatory markers with a combined comparative measurement of WBC, CRP, and SAA pre-operatively, at day 1, 3, 7, and 14 and upon presentation with suspected SSI (65).

\section{IMAGING}

Imaging is considered a key element for the diagnosis and followup of SSI following spine surgery. Even though magnetic resonance imaging (MRI) remains the technique of choice, plain X-ray has always been the first to be ordered when suspecting an SSI. However, this imaging lacks sensitivity in detecting SSI, which can cause delays in the establishment of a definitive diagnosis $(12,67)$. In fact, post-operative plain radiographs performed up until 4 weeks post index procedure, are expected to show normal or unchanged spinal structure compared to pre-operative images $(2,67)$. The first pathologically defining change to appear between the fourth and sixth weeks post-operatively is a decrease in intervertebral height. Other plain radio film manifestations, including osteolysis, deformity, and endplate destruction, are only expected to appear after 6 weeks $(2,67)$.

As for CT scanning, interest was lost in this technique after the advent and widespread availability of MRI. However, CT scan imaging can be used to assess bony destruction and spinal stability with great precision $(2,9)$. It can aid in planning transcutaneous aspiration and in the surgical approach and technique.

Radionuclide imaging has shown higher sensitivity and earlier detection of SSI compared to CT scanning and X-ray imaging. For instance, Gallium 67 scanning can show focal increased uptake areas suggestive of infection with high sensitivity and specificity of 89 and $85 \%$, respectively $(2,68,69)$. Moreover, it is estimated that the interval for the appearance of diagnostic radiological signs of SSI is shortened with Gallium 67 compared to Technetium 99 scanning $(2,68,69)$, rendering Gallium 67 the preferred agent for early detection of SSI radiological changes.

Magnetic resonance imaging is currently the most appropriate imaging to be performed as a first step when suspecting SSIs $(70,71)$. MRI is both the most sensitive (93\%) and specific (96\%) technique to evaluate SSIs following spine surgery $(72,73)$. The diagnostic features of SSI can be detected as early as days 3-5 post-operatively. Characteristic findings include diminished disk height, vertebral body, and disk space, decreased intensity on T1-weighted images, increased signal intensity on T2-weighted imaging secondary to edema, and endplate definition loss. These vertebral disk changes are accompanied by increased bone marrow intensity signaling due to edema (74).

Early in the infection process, short tau inversion recovery (STIR) sequences offer higher signal intensity to help differentiate the infected area from the normal spine, but with a drawback of inferior anatomic detail (73). Although MRI remains the imaging of choice, many limitations hamper its role in the diagnosis of SSI. Diagnostic findings depend on many technical parameters, and artifacts from implants may hinder the interpretation of results $(76,77)$. In addition, some degenerative or inflammatory non-infectious diseases may simulate spinal infection leading to a false positive result $(75,76)$. Moreover, an important limitation involves the follow-up of patients with SSIs. There is often no noted difference in the MRI between patients who have shown clinical improvement and those who did not (77). Thus, the clinicians' interpretation of follow-up MRI results should focus on soft tissue rather than bony findings, keeping in mind that no single parameter in MRI results is significantly correlated with the clinical status variation (77).

Many studies have been recently undertaken to define the imaging technique that will resolve the above-mentioned controversies and limitations surrounding the radiological diagnosis of SSI following spine surgery. 18F-fluorodeoxyglucose-positron emission tomography (FDG-PET) imaging is one modality that has lately shown utility in patients with suspected SSI (76). In a prospective cohort study that assessed over 300 patients, Ohtori et al. found that a definitive diagnosis of SSI was achieved more often when 18FDG-PET was utilized (78). This was reported specifically in patients with spinal infections presenting as Modic type 1 signal on MRI, which made the distinction between common Modic changes and SSI challenging $(78,79)$. The benefit of 18 FDG-PET imaging is its usefulness in the work-up of patients with metallic implants, since it is not affected by artifacts. In fact, 18FDG-PET imaging is characterized by high sensitivity and specificity and can provide results within $2 \mathrm{~h}$ with a resolution of up to $4-5 \mathrm{~mm}$. In addition, it entails a relatively low exposure to radiation and helps in distinguishing between initial spondylodiscitis and degenerative changes in the vertebral body endplate (79). One limitation of this technique is that it is difficult at times to distinguish an infectious process from a malignancy (80). However, in the right clinical setting, this is not expected to be an issue in the postoperative period. Unfortunately, due to its high cost and limited availability, the use of this technique remains limited, and it is indicated as a second line option for complicated cases with significant 
delay in the establishment of a definitive diagnosis, or when MRI is contraindicated (78-81).

\section{ETIOLOGICAL DIAGNOSIS}

The isolation of a specific pathogen is of crucial importance in the diagnosis and management of SSIs following spine surgery. Blood cultures (two to four sets) constitute the simplest procedure to detect the pathogen. When the blood culture yields a highly pathogenic organism such as $S$. aureus, $P$. aeruginosa, and no other sites of infections are obvious, then this is diagnostic of the causative agent. However, blood cultures lack both sensitivity and specificity in detecting the pathogen (82).

Superficial infections do not pose significant controversies and their diagnosis is more obvious than that of deep infections. In superficial spine infections, Gram stain and culture of wound swabs or aspirated fluid are recommended. Although very easy to perform, wound swab cultures lack specificity due to contamination by normal skin flora. In contrast, deep-seated spine infections require CT or fluoroscopic-guided deep aspiration from the infected area. This has shown a low diagnostic yield of around $40 \%$ when compared to cultures from intraoperative infected tissue, which remains the most reliable method of pathogen detection. Previous use of antibiotics is the main reason for the low diagnostic yield of fluoroscopic-guided aspiration (82-85). However, since the procedure has already been established to be both safe and minimally invasive, it should be done in all patients with deep-seated infections with negative blood cultures.

Three main recommendations may help in improving the diagnostic yield and avoiding false negative cultures. First, the use of a large bore needle is encouraged (86). Second, histopathological examination should be requested as an adjunct to cultures if adequate tissue can be safely obtained, since this can help identify pyogenic from granulomatous changes in tissues. The use of additional staining for fungi and mycobacteria is highly advised, especially with previous negative culture results (87-90). Third, a delay in antibiotic therapy is recommended in order to achieve a better culture yield of aspirated specimens (52). This should be balanced with potential consequences of delayed treatment. In patients with normal neurologic examination and normal hemodynamic status and who had been started on antibiotics before the performance of CT-guided aspiration, withholding therapy for 1 week before performing the procedure is advisable. However, for patients with neurological compromise, broad-spectrum empiric antibiotic therapy and immediate surgical intervention are warranted (91).

These recommendations are intended to maximize the yield of cultures obtained from CT-guided aspirations. However, if cultures are negative, the patient's neurological and hemodynamic status is of pivotal importance in determining the best next step in clinical practice. Repeating the percutaneous aspiration is recommended if the patient has a normal neurological evaluation, is hemodynamically stable, and has no major underlying morbidities (92, 93). Conversely, in patients who present with deteriorating general or neurological status, rapid intervention is crucial to improve patient outcome. Surgical intervention is recommended, along with obtaining cultures of intra-operative specimens, since this has shown increased diagnostic yield even if minimally invasive techniques had been used for sampling (94-96).

Two techniques have improved the yield of microbiologic confirmation of the offending organism. First, the use of novel DNA microarrays and polymerase chain reaction (PCR) molecular amplification techniques of aspirated or sampled tissues and fluid during surgery or percutaneous aspiration and biopsy have shown high sensitivity and specificity and could be instrumental in defining the etiological diagnosis of SSI (97-102). This technique offers a particular advantage in patients with prior antibiotic use. In addition to classical bacterial pathogens, PCR amplification can effectively detect mycobacterial species. Given the extremely elevated morbidity and neurological dysfunction associated with untreated spine infections, these molecular techniques may help in obtaining a quick definitive diagnosis of SSI and prompt an earlier initiation of targeted antibiotherapy (97102). However, susceptibility testing cannot be obtained through molecular testing, highlighting the superiority of cultures.

Second, vortexing and sonication of retrieved spinal implants to disrupt the biofilms has been recommended. Even though this technique is not widely available for daily practice, it has shown a sensitivity of $93 \%$ and a specificity of $97 \%$ in the isolation of pathogens involved in SSIs following spine surgery (48). Additional efforts are needed to increase availability, accessibility, and utilization of these new methods (48).

\section{CONCLUSION}

Surgical site infection following spine surgery is a major cause of increased morbidity following spine interventions and an immense burden on the health care system. A high index of suspicion should be kept in the first 3 months after the procedure. The diagnosis is usually suspected based on the symptoms and physical exam findings. However, a number of laboratory and imaging techniques are available to speed up the confirmation of the diagnosis and the recovery of the offending organisms, which would allow early targeted therapy.

\section{REFERENCES}

1. Turnbull F. Postoperative inflammatory disease of lumbar discs. J Neurosurg (1953) 10:469-73. doi:10.3171/jns.1953.10.5.0469

2. Rawlings CE, Wilkins RH, Gallis HA, Goldner JL, Francis R. Postoperative intervertebral disc space infection. Neurosurgery (1983) 13:371-6. doi:10.1227/ 00006123-198310000-00004

3. Dobzyniak MA, Fischgrund JS, Hankins S, Herkowitz HN. Single versus multiple dose antibiotic prophylaxis in lumbar disc surgery. Spine (2003) 28:E453-5. doi:10.1097/01.BRS.0000090839.61893.BE

4. Abbey DM, Turner DM, Warson JS, Wirt TC, Scalley RD. Treatment of postoperative wound infections following spinal fusion with instrumentation. J Spinal Disord (1995) 8:278-83. doi:10.1097/00002517-199508040-00003

5. Sponseller PD, Laporte DM, Hungerford MW, Eck K, Bridwell KH, Lenke LG. Deep wound infections after neuromuscular scoliosis surgery: a multicenter study of risk factors and treatment outcomes. Spine (2000) 25:2461-6. doi:10.1097/00007632-200010010-00007

6. Barker FG II. Efficacy of prophylactic antibiotic therapy in spinal surgery: a meta-analysis. Neurosurgery (2002) 51:391-401. doi:10.1227/00006123200208000-00017

7. Calderone RR, Garland DE, Capen DA, Oster H. Cost of medical care for postoperative spinal infections. Orthop Clin North Am (1996) 27:171-82.

8. Whitmore RG, Stephen J, Stein SC, Campbell PG, Yadla S, Harrop JS, et al. Patient comorbidities and complications after spinal surgery: a societal-based cost analysis. Spine (2012) 37:1065-71. doi:10.1097/BRS.0b013e31823da22d 
9. Nasto LA, Colangelo D, Rossi B, Fantoni M, Pola E. Post-operative spondylodiscitis. Eur Rev Med Pharmacol Sci (2012) 16:50-7.

10. Bavinski G, Schoeggl A, Trattnig S, Standhardt H, Dietrich W, Reddy M, et al. Microsurgical management of postoperative disc infection. Neurosurg Rev (2003) 26:102-7. doi:10.1007/s10143-002-0241-x

11. Jimenez-Mejias ME, de Dios CJ, Sanchez-Lora FJ, Palomino-Nicás J, Reguera JM, García de la Heras J, et al. Postoperative spondylodiscitis: etiology, clinical findings, prognosis, and comparison with nonoperative pyogenic spondylodiscitis. Clin Infect Dis (1999) 29:339-45. doi:10.1086/520212

12. Silber JS, Anderson DG, Vaccaro AR, Anderson PA, McCormick P. Management of postprocedural discitis. Spine (2002) 2:279-87. doi:10.1016/S15299430(02)00203-6

13. Bircher MD, Tasker T, Crashaw C, Mulholland RC. Discitis following lumbar surgery. Spine (1988) 13:98-102. doi:10.1097/00007632-198801000-00023

14. Dauch WA. Infection of the intervertebral space following conventional and microsurgical operation on the herniated lumbar intervertebral disc: a controlled clinical trial. Acta Neurochir (1986) 82:43-9. doi:10.1007/BF01456318

15. Rechtine GR, Bono PL, Cahill D, Bolesta MJ, Chrin AM. Postoperative wound infection after instrumentation of thoracic and lumbar fractures. J Orthop Trauma (2001) 15:566-9. doi:10.1097/00005131-200111000-00006

16. Best NM, Sasso RC. Success and safety in outpatient microlumbar discectomy. $J$ Spinal Disord Tech (2006) 19:334-7. doi:10.1097/01.bsd.0000210119.47387.44

17. Weinstein JN, Tosteson TD, Lurie JD, Skinner JS, Hanscom B, Tosteson AN, et al. Surgical vs nonoperative treatment for lumbar disk herniation: the Spine Patient Outcomes Research Trial (SPORT): a randomized trial. JAMA (2006) 296:2441-50. doi:10.1001/jama.296.20.2441

18. Beiner JM, Grauer J, Kwon BK, Vaccaro AR. Postoperative wound infections of the spine. Neurosurg Focus (2003) 15:E14. doi:10.3171/foc.2003.15.3.14

19. Morgan-Hough CV, Jones PW, Eisenstein SM. Primary and revision lumbar discectomy. A 16-year review from one centre. J Bone Joint Surg Br (2003) 85:871-4.

20. Smith JS, Shaffrey CI, Sansur CA, Berven SH, Fu KG, Broadstone PA. Rates of infection after spine surgery based on 108,419 procedures. Spine (2011) 36:556-63. doi:10.1097/BRS.0b013e3181eadd41

21. O'Toole JE, Eichholz KM, Fessler RG. Surgical site infection rates after minimally invasive spinal surgery. J Neurosurg Spine (2009) 11:471-6. doi:10.3171/ 2009.5.SPINE08633

22. Valentini LG, Casali C, Chatenoud L, Chiaffarino F, Uberti-Foppa C, Broggi G. Surgical site infections after elective neurosurgery: a survey of 1747 patients. Neurosurgery (2008) 62:88-96. doi:10.1227/01.NEU.0000311065.95496.C5

23. Olsen MA, Nepple JJ, Riew KD, Lenke LG, Bridwell KH, Mayfield J, et al. Risk factors for surgical site infection following orthopaedic spinal operations. J Bone Joint Surg Am (2008) 90:62-9. doi:10.2106/JBJS.F.01515

24. Friedman ND, Sexton DJ, Connelly SM, Kaye KS. Risk factors for surgical site infection complicating laminectomy. Infect Control Hosp Epidemiol (2007) 28:1060-5. doi:10.1086/519864

25. Collins I, Wilson-MacDonald J, Chami G, Burgoyne W, Vineyakam P, Berendt $\mathrm{T}$, et al. The diagnosis and management of infection following instrumented spinal fusion. Eur Spine J (2008) 17:445-50. doi:10.1007/s00586-0070559-8

26. Kanayama M, Hashimoto T, Shigenobu K, Oha F, Togawa D. Effective prevention of surgical site infection using a Centers for Disease Control and Prevention guideline-based antimicrobial prophylaxis in lumbar spine surgery. J Neurosurg Spine (2007) 6:327-9. doi:10.3171/spi.2007.6.4.7

27. Mirovsky Y, Floman Y, Smorgick Y, Ashkenazi E, Anekstein Y, Millgram MA, et al. Management of deep wound infection after posterior lumbar interbody fusion with cages. J Spinal Disord Tech (2007) 20:127-31. doi:10.1097/01.bsd. 0000211266.66615.e5

28. Pappou IP, Papadopoulos EC, Sama AA, Girardi FP, Cammisa FP. Postoperative infections in interbody fusion for degenerative spinal disease. Clin Orthop Relat Res (2006) 444:120-8. doi:10.1097/01.blo.0000203446.06028.b5

29. Fang A, Hus S, Endres N, Bradford DS. Risk factors for infection after spinal surgery. Spine (2005) 30:1460-5. doi:10.1097/01.brs.0000166532.58227.4f

30. Olsen MA, Mayfield J, Lauryssen C, Polish LB, Jones M, Vest J, et al. Risk factors for surgical site infection in spinal surgery. J Neurosurg (2003) 98:149-55.

31. Gaynes RP, Culver DH, Horan TC, Edwards JR, Richards C, Tolson JS. Surgical site infection (SSI) rates in the United States, 1992-1998: the National
Nosocomial Infections Surveillance System basic SSI risk index. Clin Infect Dis (2001) 33:S69-77. doi:10.1086/321860

32. Picada R, Winter RB, Lonstein JE, Denis F, Pinto MR, Smith MD, et al. Postoperative deep wound infection in adults after posterior lumbosacral spine fusion with instrumentation: incidence and management. J Spinal Disord (2000) 13:42-5. doi:10.1097/00002517-200002000-00009

33. Kanafani ZA, Dakdouki GK, El-Dbouni O, Bawwab T, Kanj SS. Surgical site infections following spinal surgery at a tertiary care center in Lebanon: incidence, microbiology, and risk factors. Scand J Infect Dis (2006) 38:589-92. doi:10.1080/00365540600606440

34. Weinstein MA, McCabe JP, Cammisa FP Jr. Postoperative spinal wound infection: a review of 2,391 consecutive index procedures. J Spinal Disord (2000) 13:422-6. doi:10.1097/00002517-200010000-00009

35. Blam OG, Vaccaro AR, Vanichkachorn JS, Albert TJ, Hilibrand AS, Minnich JM, et al. Risk factors for surgical site infection in the patient with spinal injury. Spine (2003) 28:1475-80. doi:10.1097/01.BRS.0000067109.23914.0A

36. Pull terGunne AF, Cohen DB. Incidence, prevalence, and analysis of risk factors for surgical site infection following adult spinal surgery. Spine (2009) 34:1422-8. doi:10.1097/BRS.0b013e3181a03013

37. Gil-Egea MJ, Pi-Sunyer MT, Verdaguer A, Sanz F, Sitges-Serra A, Eleizegui LT. Surgical wound infections: prospective study of 4486 clean wounds. Infect Control (1987) 8:277-80.

38. Koutsoumbelis S, Hughes AP, Girardi FP, Cammisa FP, Finerty EA, Nguyen JT. Risk factors for postoperative infection following posterior lumbar instrumented arthrodesis. J Bone Joint Surg Am (2011) 93:1627-33. doi:10.2106/JBJS. J.00039

39. Mangram AJ, Horan TC, Pearson ML, Silver LC, Jarvis WR. Guideline for prevention of surgical site infection, 1999. Hospital Infection Control Practices Advisory Committee. Infect Control Hosp Epidemiol (1999) 20:247-78.

40. Cizik A, Lee M, Martin B, Bransford R, Bellabarba C, Chapman J, et al. Using the spine surgical invasiveness index to identify risk of surgical site infection. J Bone Joint Surg Am (2012) 94:335-42. doi:10.2106/JBJS.J.01084

41. Campbell PG, Malone J, Yadla S, Maltenfort MG, Harrop JS, Sharan AD, et al. Early complications related to approach in thoracic and lumbar spine surgery: a single center prospective study. World Neurosurg (2010) 73:395-401. doi:10.1016/j.wneu.2010.01.024

42. Maragakis LL, Cosgrove SE, Martinez EA, Tucker MG, Cohen DB, Perl TM. Intraoperative fraction of inspired oxygen is a modifiable risk factor for surgical site infection after spinal surgery. Anesthesiology (2009) 110:556-62. doi:10.1097/ALN.0b013e3181974be7

43. Veeravagu A, Patil CG, Lad SP, Boakye M. Risk factors for postoperative spinal wound infections after spinal decompression and fusion surgeries. Spine (2009) 34:1869-72. doi:10.1097/BRS.0b013e3181adc989

44. Gerometta A, Rodriguez Olaverri JC, Bitan F. Infections in spinal instrumentation. Int Orthop (2012) 36:457-64. doi:10.1007/s00264-011-1426-0

45. The Centers for Disease Control and Prevention. Your Guide to the Standardized Infected Ratio (SIR). NHSN (2010). Available from: http://www.cdc.gov/nhsn/ PDFs/Newsletters/NHSN_NL_OCT_2010SE_final.pdf

46. Yoon SH, Ugrinow VL, Upasani VV, Pawelek JB, Newton PO. Comparison between $4.0-\mathrm{mm}$ stainless steel and $4.75-\mathrm{mm}$ titanium alloy single-rod spinal instrumentation for anterior thoracoscopic scoliosis surgery. Spine (2008) 33:2173-8. doi:10.1097/BRS.0b013e31817f9415

47. Lillie P, Thaker H, Moss P, Baruah J, Cullen L, Taylor D, et al. Healthcare associated discitis in the era of antimicrobial resistance. J Clin Rheumatol (2008) 14:234-7. doi:10.1097/RHU.0b013e31818laddd

48. Sampedro MF, Huddleston PM, Piper KE, Karau MJ, Dekutoski MB, Yaszemski MJ, et al. A biofilm approach to detect bacteria from removed spinal implants. Spine (2010) 35:1218-24. doi:10.1097/BRS.0b013e3181c3b2f3

49. Pull terGunne AF, Mohamed AS, Skolasky RL, van Laarhoven CJ, Cohen DB. The presentation, incidence, etiology, and treatment of surgical site infections after spinal surgery. Spine (2010) 35:1323-8. doi:10.1097/BRS. 0b013e3181bcde61

50. Hopkinson N, Stevenson J, Benjamin S. A case ascertainment study of septic discitis: clinical, microbiological and radiological features. Q J Med (2001) 94:465-70. doi:10.1093/qjmed/94.9.465

51. Massie JB, Heller JG, Abitbol JJ, McPherson D, Garfin SR. Postoperative posterior spinal wound infections. Clin Orthop Relat Res (1992) 284:99-108. 
52. McDermott H, Bolger C, Humphreys H. Postprocedural discitis of the vertebral spine: challenges in diagnosis, treatment and prevention. J Hosp Infect (2012) 82:152-7. doi:10.1016/j.jhin.2012.07.009

53. Bémer P, Corvec S, Tariel S, Asseray N, Boutoille D, Langlois C, et al. Significance of Propionibacterium acnes positive samples in spinal instrumentation. Spine (2008) 33:E971-6. doi:10.1097/BRS.0b013e31818e28dc

54. Harris AE, Hennicke C, Byers K, Welch WC. Postoperative discitis due to Propionibacterium acnes: a case report and review of the literature. Surg Neurol (2005) 63:538-41. doi:10.1016/j.surneu.2004.06.012

55. Uçkay I, Dinh A, Vauthey L, Asseray N, Passuti N, Rottman M, et al. Spondylodiscitis due to Propionibacterium acnes: report of twenty-nine cases and a review of the literature. Clin Microbiol Infect (2010) 16:353-8. doi:10.1111/j. 1469-0691.2009.02801.x

56. Jakab E, Zbinden R, Gubler J, Ruef C, von Graevenitz A, Krause M. Severe infections caused by Propionibacterium acnes: an underestimated pathogen in late postoperative infections. Yale J Biol Med (1996) 69:477-82.

57. Dall BE, Rowe DE, Odette WG, Batts DH. Postoperative discitis. Diagnosis and management. Clin Orthop Relat Res (1987) 224:138-46.

58. Hadjipavlou AG, Mader JT, Necessary JT, Muffoletto AJ. Hematogenous pyogenic spinal infections and their surgical management. Spine (2000) 25:1668-79. doi:10.1097/00007632-200007010-00010

59. Kang BU, Lee SH, Ahn Y, Choi WC, Choi YG. Surgical site infection in spinal surgery: detection and management based on serial C-reactive protein measurements. J Neurosurg Spine (2010) 13:158-64. doi:10.3171/2010.3. SPINE09403

60. Thelander U, Larsson S. Quantitation of C-reactive protein levels and erythrocyte sedimentation rate after spinal surgery. Spine (1992) 17:400-4. doi:10.1097/00007632-199204000-00004

61. Jonsson B, Soderholm R, Stromqvist B. Erythrocyte sedimentation rate after lumbar spine surgery. Spine (1991) 16:1049-50. doi:10.1097/00007632199109000-00006

62. Mok JM, Pekmezci M, Piper SL, Boyd E, Berven SH, Burch S, et al. Use of C-reactive protein after spinal surgery. Spine (2008) 33:415-21. doi:10.1097/ BRS.0b013e318163f9ee

63. Kapp JP, Sybers WA. Erythrocyte sedimentation rate following uncomplicated lumbar disc operations. Surg Neurol (1979) 12:329-30.

64. Takahashi J, Ebara S, Kamimura M, Kinoshita T, Itoh H, Yuzawa Y, et al. Earlyphase enhanced inflammatory reaction after spinal instrumentation surgery. Spine (2001) 26:1698-704. doi:10.1097/00007632-200108010-00014

65. Deguchi M, Shinjo R, Yoshioka Y, Seki H. The usefulness of serum amyloid A as a post-operative inflammatory marker after posterior lumbar interbody fusion. J Bone Joint Surg Br (2010) 92:555-9. doi:10.1302/0301-620X.92B4.22807

66. Maus U, Anderega S, Gravius S, Ohnsorge JA, Miltner O. Procalcitonin (PTC) as a diagnostic tool for monitoring of spondylodiscitis. Z Orthop Unfall (2009) 147:59-64. doi:10.1055/s-2008-1038974

67. Tyrrell PN, Cassar-Pullicino VN, McCall IW. Spinal infection. Eur Radiol (1999) 9:1066-77. doi:10.1007/s003300050793

68. Bruschwein DA, Brown ML, McLeod RA. Gallium scintigraphy in the evaluation of disk-space infections: concise communication. J Nucl Med (1980) 21:925-7.

69. Norris S, Ehrlich MG, Keim DE, Guiterman H, McKusick KA. Early diagnosis of disc-space infection using Gallium-67. J Nucl Med (1978) 19:384-6.

70. Hoelscher GL, Gruber HE, Coldham G, Grigsby JH, Hanley EN. Effects of very high antibiotic concentrations on human intervertebral disc cell proliferation, viability, and metabolism in vitro. Spine (2000) 25:1871-7. doi:10.1097/00007632-200008010-00003

71. Blankstein A, Rubenstein E, Ezra E, Lokeic F, Capsi I, Horoszowski H. Disc space infection and vertebral osteomyelitis as a complication of percutaneous lateral discectomy. Clin Orthop Relat Res (1987) 225:234-7.

72. Vaccaro AR, Shah SH, Schweitzer ME, Rosenfeld JF, Cotler JM. MRI description of vertebral osteomyelitis, neoplasm, and compression fracture. Orthopedics (1999) 22:67-73.

73. Djukic S, Genant HK, Helms CA, Holt RG. Magnetic resonance imaging of the postoperative lumbar spine. Radiol Clin North Am (1990) 28:341-60.

74. Dagirmanjian A, Schils J, McHenry M, Modic MT. MR imaging of vertebral osteomyelitis revisited. AJR Am J Roentgenol (1996) 167:1539-43. doi:10.2214/ajr.167.6.8956593
75. Hong SH, Choi JY, Lee JW, Kim NR, Choi JA, Kang HS. MR imaging assessment of the spine: infection or an imitation? Radiographics (2009) 29:599-612. doi:10.1148/rg.292085137

76. Che W, Li RY, Dong J. Progress in diagnosis and treatment of cervical postoperative infection. Orthop Surg (2011) 3:152-7. doi:10.1111/j.1757-7861.2011. 00140.x

77. Kowalski TJ, Layton KF, Berbari EF, Steckelberg JM, Huddleston PM, Wald JT, et al. Follow-up MR imaging in patients with pyogenic spine infections: lack of correlation with clinical features. AJNR Am J Neuroradiol (2007) 28: 693-9.

78. Ohtori S, Suzuki M, Koshi T, Yamashita M, Yamauchi K, Inoue G, et al. Diffusion magnetic resonance imaging to differentiate degenerative from infectious endplate abnormalities in the lumbar spine. Spine (2011) 36:E198-202. doi:10.1097/BRS.0b013e3181d5ff05

79. Glaudemans AW, Signore A. FDG-PET/CT in infections: the imaging method of choice? Eur J Nucl Med Mol Imaging (2010) 37:1986-91. doi:10.1007/ s00259-010-1587-x

80. Gemmel F, Rijk PC, Collins JM, Parlevliet T, Stumpe KD, Palestro CJ. Expanding role of $18 \mathrm{~F}$-fluoro-D-deoxyglucose $\mathrm{PET}$ and $\mathrm{PET} / \mathrm{CT}$ in spinal infections. Eur Spine J (2010) 19:540-51. doi:10.1007/s00586-009-1251-y

81. Stumpe KD, Zanetti M, Weishaupt D, Hodler J, Boos N, Von Schulthess GK. FDG positron emission tomography for differentiation of degenerative and infectious endplate abnormalities in the lumbar spine detected on MR imaging. AJR Am J Roentgenol (2002) 179:1151-7. doi:10.2214/ajr.179.5. 1791151

82. Enoch DA, Cargill JS, Laing R, Herbert S, Corrah TW, Brown NM. Value of CTguided biopsy in the diagnosis of septic discitis. J Clin Pathol (2008) 6:750-3. doi:10.1136/jcp.2007.054296

83. Chaudhary SB, Vives MJ, Basra SK, Reiter MF. Postoperative spinal wound infections and postprocedural discitis. J Spinal Cord Med (2007) 30:441-51.

84. Rieneck K, Hansen SE, Karle A, Gutschik E. Microbiologically verified diagnosis of infectious spondylitis using CT-guided fine needle biopsy. APMIS (1996) 104:755-62. doi:10.1111/j.1699-0463.1996.tb04939.x

85. Omarini LP, Garcia J. CT-guided percutaneous puncture-biopsy of the spine. Review of 104 cases. Schweiz Med Wochenschr (1993) 123:2191-7.

86. Skaf GS, Domloj NT, Fehlings MG, Bouclaous CH, Sabbagh AS, Kanafani ZA, et al. Pyogenic spondylodiscitis: an overview. J Infect Public Health (2010) 3:5-16. doi:10.1016/j.jiph.2010.01.001

87. Chew FS, Kline MJ. Diagnostic yield of CT-guided percutaneous aspiration procedures in suspected spontaneous infectious discitis. Radiology (2001) 218:211-4. doi:10.1148/radiology.218.1.r01ja06211

88. Hadjipavlou AG, Kontakis GM, Gaitanis JN, Katonis PG, Lander P, Crow WN. Effectiveness and pitfalls of percutaneous transpedicle biopsy of the spine. Clin Orthop Relat Res (2003) 41 1:54-60. doi:10.1097/01.blo.0000068184. 83581.86

89. Rankine JJ, Barron DA, Robinson P, Millner PA, Dickson RA. Therapeutic impact of percutaneous spinal biopsy in spinal infection. Postgrad Med J (2004) 80:607-9. doi:10.1136/pgmj.2003.017863

90. Frazier DD, Campbell DR, Garvey TA, Wiesel S, Bohlman HH, Eismont FJ. Fungal infections of the spine. Report of eleven patients with long-term follow-up. J Bone Joint Surg Am (2001) 83-A:560-5.

91. Zimmerli W. Clinical practice. Vertebral osteomyelitis. N Engl J Med (2010) 362:1022-9. doi:10.1056/NEJMcp0910753

92. Grados F, Lescure FX, Senneville E, Flipo RM, Schmit JL, Fardellone P. Suggestions for managing pyogenic (non-tuberculous) discitis in adults. Joint Bone Spine (2007) 74:133-9.

93. Société de Pathologie Infectieuse de Langue Française (SPILF). Primary infectious spondylitis, and following intradiscal procedure, without prothesis. Med Mal Infect (2007) 37:554-72.

94. Lew DP, Waldvogel FA. Osteomyelitis. Lancet (2004) 364:369-79. doi:10.1016/ S0140-6736(04)16727-5

95. Yang SC, Fu TS, Chen LH, Chen WJ, Tu YK. Identifying pathogens of spondylodiscitis: percutaneous endoscopy or CT-guided biopsy. Clin Orthop Relat Res (2008) 466:3086-92. doi:10.1007/s11999-008-0441-y

96. Lucio E, Adesokan A, Hadjipavlou AG, Crow WN, Adegboyega PA. Pyogenic spondylodiscitis: a radiologic/pathologic and culture correlation study. Arch Pathol Lab Med (2000) 124:712-6. 
97. Harris KA, Hartley JC. Development of broad-range 16S rDNA PCR for use in the routine diagnostic clinical microbiology service. J Med Microbiol (2003) 52:685-91. doi:10.1099/jmm.0.05213-0

98. Fenollar F, Levy PY, Raoult D. Usefulness of broad-range PCR for the diagnosis of osteoarticular infections. Curr Opin Rheumatol (2008) 20:463-70. doi:10.1097/BOR.0b013e3283032030

99. Fuursted K, Arpi M, Lindblad BE, Pedersen LN. Broad-range PCR as a supplement to culture for detection of bacterial pathogens in patients with a clinically diagnosed spinal infection. Scand J Infect Dis (2008) 40:772-7. doi:10.1080/00365540802119994

100. Ribeiro MA, Barouni AS, Augusto CJ, Augusto MV, Lopes MT, Salas CE. PCR identification of Mycobacterium tuberculosis complex in a clinical sample from a patient with symptoms of tuberculous spondylodiscitis. Braz J Med Biol Res (2007) 40:1-4. doi:10.1590/S0100-879X2007000100001

101. Verettas D, Kazakos C, Tilkeridis C, Dermon A, Petrou H, Galanis V. Polymerase chain reaction for the detection of Mycobacterium tuberculosis in synovial fluid, tissue samples, bone marrow aspirate and peripheral blood. Acta Orthop Belg (2003) 69:396-9.

102. Fenollar F, Roux V, Stein A, Drancourt M, Raoult D. Analysis of 525 samples to determine the usefulness of PCR amplification and sequencing of the $16 \mathrm{~S}$
rRNA gene for diagnosis of bone and joint infections. J Clin Microbiol (2006) 44:1018-28. doi:10.1128/JCM.44.3.1018-1028.2006

Conflict of Interest Statement: The authors declare that the research was conducted in the absence of any commercial or financial relationships that could be construed as a potential conflict of interest.

Received: 31 August 2013; accepted: 13 March 2014; published online: 24 March 2014. Citation: Chahoud J, Kanafani $Z$ and Kanj SS (2014) Surgical site infections following spine surgery: eliminating the controversies in the diagnosis. Front. Med. 1:7. doi: 10.3389/fmed.2014.00007

This article was submitted to Infectious Diseases, a section of the journal Frontiers in Medicine.

Copyright (C) 2014 Chahoud, Kanafani and Kanj. This is an open-access article distributed under the terms of the Creative Commons Attribution License (CC BY). The use, distribution or reproduction in other forums is permitted, provided the original author(s) orlicensor are credited and that the original publication in this journal is cited, in accordance with accepted academic practice. No use, distribution or reproduction is permitted which does not comply with these terms. 